\title{
Vibração transversal: Um método eficiente para classificação de peças estruturais de madeira
}

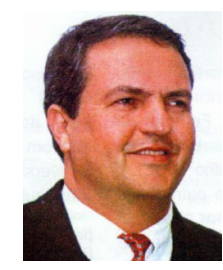

Carlito Calil Júnior ${ }^{1} \&$ Alexandre J. S. Miná

\author{
1 SET/LaMEM/EESC/USP. Av. Trab. São Carlense, 4000, Centro. CEP 13560-970, São Carlos, SP. Fone: (16) $273-9320$. \\ E-mail: calil@sc.usp.br (Foto) \\ 2 DTR/CFT/UFPB. CEP 58220-000, Bananeiras, PB. Fone: (16) 273-9369. E-mail:alexpb@sc.usp.br
}

Protocolo 101 - 19/7/2002 - Aprovado em 4/8/2003

\begin{abstract}
Resumo: A classificação de peças estruturais de madeira é uma tendência mundial, mas ainda deficiente no Brasil. O uso de métodos não-destrutivos para classificação e, conseqüentemente, para racionalização do uso de madeira em estruturas, melhora a posição da madeira quando em competição com materiais estruturais mais uniformes. Este trabalho mostra a existência de forte correlação linear entre o módulo de elasticidade estático e o módulo de elasticidade dinâmico, obtidos a partir de testes de flexão estática e de vibração transversal, em 326 peças estruturais de madeira da espécie Southern Pine, e indica a eficiência do método de vibração transversal para determinação do módulo de elasticidade e para classificação de peças estruturais de madeira.
\end{abstract}

Palavras-chave: madeira para estruturas, vibração transversal, classificação

\section{Transverse vibration: An efficient method for structural timber classification}

\begin{abstract}
The classification of structural components of timber is a worldwide tendency but is still deficient in Brazil. The application of nondestructive methods for classification and consequently, optimization of the use of timber in structures improves the position of the timber in comparison to more uniform structural materials. This work shows the existence of high linear correlation between the static elasticity modulus and the dynamic elasticity modulus, obtained from flexion static test and from transverse vibration test, in 326 structural pieces of Southern Pine specie, and indicates the efficiency of the transverse vibration test for elasticity modulus determination and for classification of structural pieces of timber.
\end{abstract}

Key words: timber structures, transverse vibration, classification

\section{INTRODUÇÃO}

A madeira apresenta grande variabilidade de suas propriedades sendo, muitas vezes, penalizada quando submetida a competição com outros materiais estruturais que possuem propriedades mecânicas mais uniformes. A classificação da madeira através do conhecimento das características de cada peça a ser usada, empregando-se testes não-destrutivos, pode ser muito útil para reverter esta situação. Peças de qualidade superior poderiam ser escolhidas para uso crítico, enquanto as de baixa qualidade poderiam ser usadas em locais onde resistência e rigidez não sejam tão importantes. Avaliação nãodestrutiva de materiais é, por definição, a ciência que identifica propriedades físicas ou mecânicas de uma peça de determinado material, sem alterar sua capacidade de uso. Segundo Bartholomeu (2001) as hipóteses fundamentais para testes não-destrutivos em madeira foram apresentadas por Jayne (1959), cuja proposta foi de que as propriedades de armazenamento e dissipação de energia na madeira são governadas pelos mesmos mecanismos que determinam o comportamento mecânico de tais materiais. Conseqüentemente, relações matemáticas entre propriedades de armazenamento e dissipação de energia na madeira, e propriedades elásticas e de resistência do material, poderiam ser obtidas através de análise estatística.

\section{Breve histórico}

A relação entre o módulo de elasticidade e a freqüência de vibração longitudinal de um teste não-destrutivo já é conhecida há quase 150 anos. Na primeira metade do século XIX, Savart, físico francês, foi o primeiro cientista a determinar o módulo de elasticidade de uma barra de ferro através de um teste de vibração. Algum tempo depois, Lager-Jhelm comparou o resultado obtido por Savart com valores obtidos através de ensaios de tração em barras de ferro. Acredita-se que esta foi a primeira tentativa de se comparar valores de constantes elásticas obtidas por meio de ensaios dinâmicos, com valores encontrados através de ensaios estáticos (Todhunter \& Pearson citado por Jayne, 1959); depois disso, muitos pesquisadores 
fizeram comparações semelhantes, usando outros tipos de ensaio e, também, de material. Para a madeira em particular, os trabalhos de Kitazawa (1950) e Bell et al. (1950), citado por Jayne (1959) demonstraram claramente a possibilidade do uso de características vibracionais para a estimativa do módulo de elasticidade estático. Jayne (1959) propôs e demonstrou com sucesso a relação entre energia de deformação e propriedades de flexão estática, cuja técnica se baseava na flexão forçada de peças. Pellerin (1965) investigou o uso da vibração transversal em vigas de madeira serrada, para determinar o módulo de elasticidade, examinando a vibração transversal livre, em vigas simplesmente apoiadas nas extremidades, e concluiu que a vibração transversal em vigas deste tipo é governada por equação diferencial, que tem solução analítica. A partir do trabalho de Pellerin (1965) muitos outros, usando metodologia semelhante, foram publicados sobre o uso do teste de vibração transversal, para determinação do módulo de elasticidade de várias espécies de madeira. Alguns trabalhos são teóricos e estudam a vibração transversal através de métodos numéricos (Murphy, 1997), mas a maioria estuda a aplicação de vibração transversal de maneira experimental, usando diversos tipos de madeira, como: madeira serrada com várias dimensões (Ross et al., 1994); toras de madeira com pequeno diâmetro (Ross et al., 2000) e madeira com ou sem defeito (Cai et al., 2000). Atualmente, o teste de vibração transversal é considerado uma técnica que apresenta valores confiáveis para o módulo de elasticidade e que pode ser usado em qualquer tipo de madeira, com qualquer seção transversal e, também, em madeira laminada colada ou, ainda, em painéis de madeira (Murphy, 2000). Também está sendo considerada pela American Society of Testing and Materials (ASTM) uma proposta para o cálculo da rigidez da madeira na flexão, usando-se um teste de vibração transversal em viga simplesmente apoiada. Esta é uma importante indicação da valorização atual do uso da vibração transversal para determinação do módulo de elasticidade da madeira.

\section{Fundamentação teórica}

Uma vibração mecânica é produzida quando um sistema é deslocado de sua situação de equilíbrio estável. O sistema tende a retornar a esta posição sob a ação de forças restauradoras, mas geralmente atinge a posição original com certa velocidade, que o leva além desta posição. Em um sistema ideal e sem a presença de forças dissipativas, o sistema permaneceria indefinidamente em movimento oscilatório em torno de sua posição de equilíbrio. O intervalo de tempo necessário para o sistema completar um ciclo inteiro do movimento é chamado período de vibração. O número de ciclos por unidade de tempo define a freqüência e o máximo deslocamento do sistema em relação à posição de equilíbrio é chamado amplitude; quando o movimento é mantido somente por forças restauradoras, diz-se que a vibração é livre; sendo uma força periódica aplicada ao sistema, o movimento resultante é descrito como vibração forçada e, quando o efeito do atrito pode ser desprezado, diz-se que a vibração é não-amortecida; caso contrário, a vibração é amortecida. Embora toda vibração seja amortecida, na maioria das estruturas reais a freqüência de vibração observada é essencialmente igual à freqüência natural de um sistema nãoamortecido. O grau de amortecimento é determinado pelo coeficiente (ou razão) de amortecimento. Na maioria das estruturas este coeficiente está entre 2 e $20 \%$. A Eq. 1 (Paz,
1984) é usada para determinação do módulo de elasticidade E, a partir do conhecimento da freqüência natural de vibração $f$, de uma viga simplesmente apoiada nas extremidades, submetida a vibração transversal livre:

$$
E=\frac{f^{2} L^{4}}{(\pi / 2)^{2} I} \frac{W}{g L}
$$

em que:

E - módulo de elasticidade

I - momento de inércia, $\mathrm{m}^{4}$

f - freqüência natural de vibração, $\mathrm{Hz}$

$\mathrm{L}$ - comprimento da viga, $\mathrm{m}$

W - peso da viga, $\mathrm{N}$

$\mathrm{g}$ - aceleração da gravidade, $\mathrm{m} \mathrm{s}^{-2}$

$\mathrm{W} / \mathrm{gL}$ - massa por unidade de comprimento da viga

\section{Teste de vibração transversal}

O procedimento para coleta de dados em um teste de vibração transversal é bastante simples. Para determinação do módulo de elasticidade de toras de madeira de pequeno diâmetro, Ross et al. (2000) usaram o seguinte procedimento: as toras foram apoiadas, de um lado, por um suporte em forma de lâmina de faca e, do outro, por um suporte pontual. Um transdutor de deslocamento foi colado na parte superior do ponto médio da tora. Naquele local, a casca foi retirada ou lixada, para melhorar o contato entre o acelerômetro e a tora. Então, a peça foi colocada em movimento oscilatório através do impacto com um martelo de borracha no meio do vão. A vibração livre da tora foi observada em um osciloscópio. O sinal verificado foi uma série de pulsos com um gradual decrescimento de amplitude. A freqüência natural foi medida e o módulo de elasticidade foi determinado através da Eq. (1). Cai et al. (2000), na determinação do módulo de elasticidade em peças de madeira nova e reaproveitada, usaram procedimento semelhante; no entanto, para medição da vibração do sistema foi usado um LVDT (Linear Variable Differential Transformer) ou transdutor indutivo de deslocamento, que é um instrumento destinado à medição de deslocamentos lineares. O sinal obtido foi observado em osciloscópio.

Em outro artigo, para determinação do módulo de elasticidade de peças de madeira serrada da espécie Southern Pine, Ross et al. (1994) usaram equipamento diferente. Para definir a freqüência natural foi utilizada uma célula de carga em um dos apoios, que estava ligada a um computador, através de uma interface.

Este trabalho tem a finalidade de apresentar um dos métodos mais promissores, no que se refere à confiabilidade dos resultados, para determinação do módulo de elasticidade e classificação de peças estruturais de madeira, o teste de vibração transversal.

\section{MATERIAL E MÉTODOS}

Com a finalidade de se avaliar o grau de relacionamento entre os módulos de elasticidade dinâmico e estático de peças 
estruturais de madeira, realizou-se um trabalho na indústria Sentinel, na cidade de Peshtigo - WI, USA, no primeiro semestre de 2001, com 326 peças estruturais de madeira, da espécie Southern Pine (pinus do sul) com umidade de $12 \%$, seção transversal de $3,81 \mathrm{~cm}(1,5$ pol. $) \times 13,97 \mathrm{~cm}(5,5$ pol. $)$ e $302,26 \mathrm{~cm}$ (119 pol.) de comprimento.

Inicialmente foi realizado, para cada peça estrutural, ensaio de vibração transversal, usando-se o modelo 340 da Metriguard para medição da freqüência natural de vibração $\mathrm{f}$, e do peso $\mathrm{W}$ das peças. Neste equipamento a peça estrutural de madeira foi simplesmente apoiada, de um lado, por um suporte em forma de lâmina de faca e, do outro, por um suporte com célula de carga, que mede a metade do peso da viga (W/2). Iniciou-se a vibração através de um leve impacto manual, não-quantificado, nas proximidades do meio do vão. Enquanto a peça estava vibrando, determinou-se a freqüência de vibração, o módulo de elasticidade dinâmico e o peso específico da peça através do processamento de sinal emitido pela célula de carga. O módulo de elasticidade dinâmico foi calculado através da Eq. (1); em seguida, realizou-se ensaio de flexão estática para determinação do módulo de elasticidade estático. Cada peça, simplesmente apoiada nas extremidades, foi submetida a uma carga concentrada de 44,48 N (10 libras) no seu ponto central, definindo-se o deslocamento vertical naquele ponto. O módulo de elasticidade estático foi encontrado a partir da fórmula da Resistência dos Materiais:

$$
\delta=\mathrm{PL}^{3} / 48 \mathrm{EI}
$$

em que:

$$
\begin{array}{ll}
\text { P } & \text { - carga aplicada }(44,48 \mathrm{~N}) \\
\mathrm{L} & \text { - vão livre da viga }(3 \mathrm{~m}) \\
\mathrm{I} & \text { - momento de inércia da seção transversal, } \mathrm{m}^{4} \\
\delta & \text { - deslocamento vertical } \\
\mathrm{E} & \text { - modulo de elasticidade estático, } \mathrm{Pa}
\end{array}
$$

\section{RESULTADOS E DISCUSSÃO}

A Tabela 1 apresenta a média e o desvio-padrão para os resultados de módulo de elasticidade encontrados pelos dois métodos, dinâmico e estático.

Tabela 1. Média e desvio-padrão para os módulos de elasticidade dinâmico e estático

\begin{tabular}{ccr} 
& \multicolumn{2}{c}{ Elasticidade - MPa } \\
\cline { 2 - 3 } & Dinâmico & Estático \\
\hline Média & 15753,7 & 15270,2 \\
Desvio-Padrão & 2299,6 & 2363,4 \\
\hline
\end{tabular}

A partir dos resultados obtidos para os módulos de elasticidade dinâmico e estático traçou-se um diagrama de dispersão: E dinâmico x E estático (Figura 1). A disposição dos pontos (E dinâmico; E estático) mostra uma clara relação linear entre as duas grandezas.

Também foram feitas as análises estatísticas de correlação linear simples, regressão linear simples e análise dos resíduos.

O coeficiente de correlação linear (r) obtido entre E dinâmico e E estático, foi de 0,98 , ou seja, existe uma forte correlação

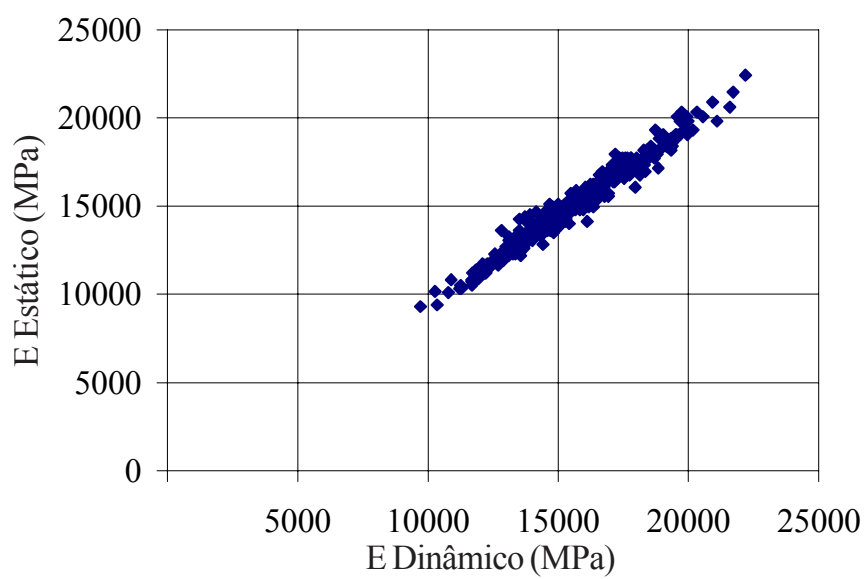

Figura 1. Diagrama de dispersão: E dinâmico X E estático, de 326 peças estruturais de madeira Southern Pine

linear entre as duas grandezas, enquanto a reta de regressão linear obtida foi: $Y=1,01 . \mathrm{X}-634,49+\mathrm{e}$; donde $\mathrm{Y}$ é a variável resposta: módulo de elasticidade estático; $\mathrm{X}$ é a variável independente: módulo de elasticidade dinâmico e e representa o resíduo, ou seja, a diferença entre o valor de E estático obtido experimentalmente e o seu valor previsto pela reta de regressão.

A análise dos resíduos mostrou que os mesmos seguem uma distribuição normal com média igual a zero e desvio-padrão igual 442,4 MPa: resíduos $\sim \mathrm{N}\left(0 ; 442,4^{2}\right)$ isto é, o valor esperado do resíduo é zero e, portanto, os valores previstos são bastante confiáveis.

\section{CONCLUSÕES}

1. Para o módulo de elasticidade dinâmico encontrou-se o valor médio de 15753,7 MPa, com desvio-padrão igual a 2299,6 $\mathrm{MPa}$, enquanto que para o módulo de elasticidade estático foi constatado o valor médio de 15270,2 MPa, com desvio-padrão igual a 2363,4 MPa.

2. Para o coeficiente de correlação linear (r) entre o módulo de elasticidade dinâmico e o módulo de elasticidade estático, obteve-se o valor de 0,98 .

3. Os resíduos seguem uma distribuição normal com média igual a zero e desvio-padrão igual a $442,4 \mathrm{MPa}$, mostrando que os valores previstos são bastante confiáveis.

4. Os resultados encontrados mostram forte correlação linear entre os módulos de elasticidade dinâmico e estático, e indicam a eficiência do método de vibração transversal para determinação do módulo de elasticidade e classificação de peças estruturais de madeira.

\section{LITERATURA CITADA}

Bartholomeu, A. Classificação de peças estruturais de madeiras através do ultra-som. Campinas: UNICAMP, 2001. 105p. Tese Doutorado

Cai, Z; Hunt, M.O; Ross, R.J; Soltis, L.A. Static and vibration moduli of elasticity of salvaged and new joists. Forest Products Journal, Madison, v.50, n.2, p.35-40, 2000.

Jayne, B.A. Vibrational properties of wood. As indices of quality. Forest Products Journal, Madison, v.9, n.11, p.413-416, 1959. 
Murphy, J.F. Transverse vibration of a simply supported beam with symmetric overhang of arbitrary length. Journal of Testing and Evaluation, Madison, v.25, n.5, p.522-524, 1997.

Murphy, J.F. Commentary on factors affecting transverse vibration using an idealized theoretical equation. Madison: Forest Products Laboratory, 2000. 4p. Research Note

Paz, M. Structural dynamics - Theory and computation, $2^{\text {nd }} e d$, New York: van Nostrand Reinhold Company, 1984. 561p.

Pellerin, R.F. A vibrational approach to nondestructive testing of structural lumber. Forest Products Journal, Madison, v.14, n.3, p.93-101, 1965.
Ross, R.J.; Ritter, M.A.; Schad, K.C. Determining in-place modulus of elasticity of stress-laminated timber decks using NDE. In: National Conference on Wood Transportation Structures, 1994, Madison: Forest Products Laboratory, 1994, p.277-281.

Ross, R.J.; Wang, X.; Mattson, J.A.; Eickson, J.R.; Forsman, J.W.; Geske, E.A.; Wehr, M.A. Comparison of several nondestructive evaluation techniques for assessing stiffness and MOE of small-diameter logs In: International Symposium on Nondestructive Testing of Wood, 12, 2000. Proceedings... Sopron: University of Western Hungary, 2000, p.155-163. 